\title{
Correlação da hemodinâmica e da mobilidade do tornozelo com o quadro clínico da doença venosa
}

\author{
Correlation of haemodynamics and ankle mobility with clinical classes of venous disease \\ Gildo Cavalheri Junior*
}

\begin{abstract}
Contexto: Na doença venosa crônica, existem alterações hemodinâmicas e da mobilidade da articulação talocrural. A gravidade desses parâmetros e suas correlações devem ser avaliadas.

Objetivo: Correlacionar os dados hemodinâmicos venosos avaliados por pletismografia a ar e dados goniométricos de amplitude de movimento do tornozelo com o quadro clínico da doença venosa, utilizando-se a classificação CEAP.

Casuística e Métodos: Foram avaliadas 142 mulheres da raça branca, 284 membros inferiores que foram distribuídos em 6 grupos, de acordo com as classes clínicas da classificação CEAP: grupo I: C0 e C1 ( $n=24)$; grupo II: C2 ( $n=30)$; grupo III: C3 ( $n=27)$; grupo IV: C4 ( $n=23)$; grupo V: C5 ( $n=20)$; grupo VI: C6 ( $n=18)$. Foram realizados os exames de goniometria da articulação do tornozelo e de pletismografia a ar. Na análise estatística, utilizou-se a análise de variância, teste de Bonferroni, Kruskal-Wallis e de Dunn, considerando erro alfa de 5\%. O estudo foi aprovado por um Comitê de Ética local e todos os participantes assinaram um termo de consentimento livre e esclarecido.

Resultados: Houve redução significante da amplitude de movimento do tornozelo nos grupos C5 e C6, comparados aos demais grupos, e no grupo C6, comparado ao C5 ( $p<0,05)$. A média do ângulo de movimento do tornozelo no grupo controle foi de $59^{\circ}$, do grupo $C 5$ foi de $43,2^{\circ}$ e do $C 6$ foi de $28,3^{\circ}$. Nos parâmetros hemodinâmicos, observou-se que o grupo controle $(0,88 \pm 0,56 \mathrm{~mL} / \mathrm{s})$ diferiu dos demais grupos em relação ao índice de enchimento venoso, e os grupos C2 (2,98 $\pm 2,62 \mathrm{~mL} / \mathrm{s})$ e C3 (3,33 $\pm 1,91 \mathrm{~mL} / \mathrm{s})$ diferiram dos grupos controle, C4 (7,34 $\pm 2,55 \mathrm{~mL} / \mathrm{s}), \mathrm{C} 5(6,46 \pm 3,49 \mathrm{~mL} / \mathrm{s})$ e C6 $(6,95 \pm 3,64 \mathrm{~mL} / \mathrm{s})(\mathrm{p}<0,05)$. Na fração de ejeção, o grupo C6 (45,71 $\pm 15,58 \%)$ diferiu dos grupos controle $(69,99 \pm 12,06 \%), \mathrm{C} 2(59,88 \pm 12,83 \%)$ e C3 (60,30 $\pm 17,07 \%)$, mas não apresentou diferença dos grupos C4 (57,35 $\pm 13,89 \%)$ e C5 (53,28 $\pm 16,34 \%)$, que se diferiram somente do grupo controle ( $<<0,05)$. Na fração de volume residual, o grupo C6 (46,02 $\pm 13,91 \%)$ diferiu dos grupos C4 (33,71 $\pm 13,92 \%), C 3(31,50 \pm 16,32 \%), C 2$ $(30,99 \pm 13,23 \%)$ e controle $(22,50 \pm 9,39 \%)(p<0,05)$. O grupo C5 $(41,41 \pm 14,78 \%)$ diferiu dos grupos controle e C2 ( $p<0,05)$. O grupo C4 diferiu dos grupos controle e C6 ( $p<0,05)$. O grupo C3 diferiu do grupo C6 ( $p<0,05)$. O grupo C2 diferiu dos grupos $C 5$ e C6 ( $<<0,05)$. O grupo controle diferiu dos grupos $C 4, C 5, C 6(p<0,05)$.

Conclusão: A doença venosa em estádios mais avançados associa-se com insuficiência das bombas impulso aspirativas do tornozelo e da panturrilha. A insuficiência valvular aumenta nos estádios clínicos C2 e C4; neste último ocorre insuficiência da bomba muscular da panturrilha e consequente hipertensão venosa durante exercícios. A fração de volume residual foi o único dado hemodinâmico que diferenciou o grupo de alterações tróficas sem ulceração do grupo ulcerado.
\end{abstract}

Palavras-chave: Insuficiência venosa; pletismografia; tornozelo; artrometria articular.

Dissertação de Mestrado defendida em 22.5.2007 na Faculdade de Medicina de São José do Rio Preto (FAMERP), São José do Rio Preto, SP.

Orientador: José Maria Pereira de Godoy**

Banca examinadora: Domingo Marcolino Braile e Guilherme Benjamim Brandão Pitta.

*Fisioterapeuta; Mestre em Ciências da Saúde pela Faculdade de Medicina de São José do Rio Preto (FAMERP), São José do Rio Preto (SP), Brasil.

Submetido em: 17.02.2008 Aceito em: 15.05 .2010

J Vasc Bras. 2010;9(4):270-270. 